\title{
SOOT PRECURSOR MATERIAL: VISUALIZATION VIA SIMULTANEOUS LIF-LII AND CHARACTERIZATION VIA TEM
}

\author{
RANDALL L. YANDER WAL \\ Nigna@ NASA-Lwis \\ Cleveland, OH 44135, USA
}

\begin{abstract}
Simultameous combined laser-induced Huorescence and laser-induced incandescence (LIF-LII) images are presented for looth a normal and inverse diflusion flame. The excitation wavelength dependence distinguishes the LIF and LII signals in images from the normal diffusion flame while the temporal decay distinguishes the signals in images of the inverse diffusion flame. Each flame presents a minimum in the combined J.IF-I II intensity in a region separating the fucl pyrolysis and soot containing regions. Opacity, geometrice definition, and extent of crystallinity me asured through both bright and dark field transmission electron microscopy (TEM) characterizes the thermoploretically sampled material from within this minimal LIF-LII intensity region. TEM andysis reveals rather different soot processes occurring within the normal and inverse diffusion Hame. In the normal diffusion flame, rapid chemical and physical coalescence of PAHs results in initial formation of soot precursor particle's that are highly crystalline and evolve toward finlly formed soot. In the inverse diffision Hatme, rapil coalescence of pyrolysis products occurs, producing tarlike, globular structures equivalent in size to fully formed soot aggregates but with markedly less cresstallinity than normal-appearing soot. These different material properties atre interpreted as reflecting dilferent relative rates of chemical and physical coalescence of fiel pyrolysis products versus carbonization. Significantly, these TEM images support qualitative photephysieal argiments sugeresting that. in gene ral. this "dark" region obsened in the I.IF-L.II imagges de nllareates at transitional region in which a fundiamental change in the mate rial che'nical/physical properties oceners between solid carbonaceous soot and condensed or gaseous molecular growth material
\end{abstract}

\section{Introduction}

The intrinsic connection between polycyclic aromatic hydrocarbons (PAIIS) and soot production within both diffusion [ $[-3]$ and premixed flames [47 ] suggests an intermediate stage or process wherehy the molecular species are transformed to solid particulate matter. An early theory of soot formation held that large liquid droplets formed by rapid condensation of fuel pyrolysis products (mainly PAHs) subsecuently transformed into soot [8]. Fue] pyro]ysis studies in shock tubes $[9]$, flow reactors [10], and premixed flame studies $[5,11]$ provide varying degrees of support for this mechamism. An altemate soot-formation process begins with small $(1-5 \mathrm{~nm}$ ), indiviclual entities called soot-precorsor particles [12]. The existence of soot-precursor particles has been inferred based on light-scattering measurements in premixed flames [13], diffirsion flames [14]. and direct visualization via transmission clectron microscopy (TFM) of sampled material in diffusion Hames $[12,15,16]$ and lonv-pressure premixed flames [H].

Although botly soot formation mechanisms begin with the coalescence of fuel pyrolysis products, the difference between these mechanisms depends on the relative rates of subsecpuent mass growth versus carbonization and will bo highly dependent on the combustion process. Carbonization in this context is understord to represent a complex series of chemical processes including but not limited to processes involving dehydrogenation and polymerization. In the former mechanism, soot mass growth is mainly completed before curbonization $[8,10]$, whereats in the latter mechanism, carbonization appears to occur faster than mass growth $[12,15]$. Support for the latter process is based on the observations of continued growth of indivichal primary particles before significant agglomeration producing aggregates $[14,17]$, the similar appearance of these individual primary particles (with diameter $>10$ mms) to those within soot aggregates [18], and laser microprobe mass analysis of soot-precursor particles revealing a hydrogen mole fraction similar to that of fully aged soot $[12,15]$

Given the critical link soot-precursor material (either as coalescing liquid droplets or soot-prexerursor particles) provides between molecular fued pyrolvsis products such as PAHs and carbonaceous soot both spattial location and characterization of the ir chemi(al/physical properties is essential in understanding soot-formation and growth processes $[8-12,15]$. No reported measurements using in situ optical technirpues have identified the spatial location of soot 


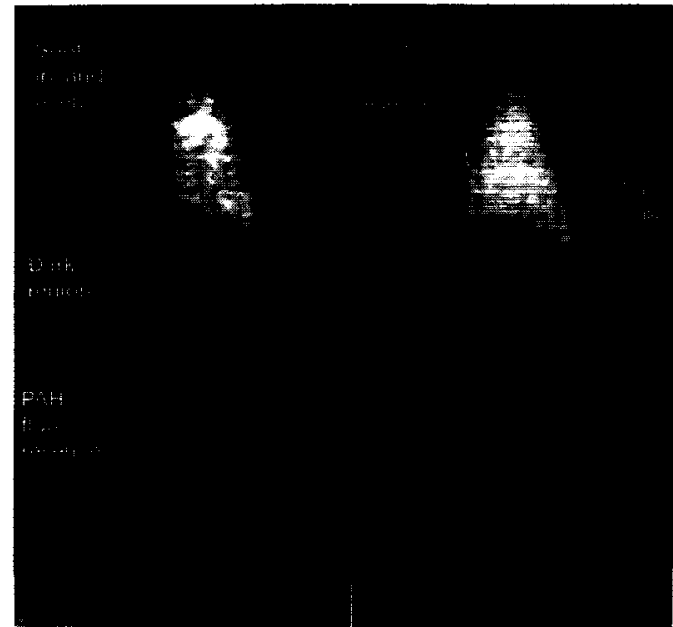

FIG. 1. (a) Simultaneous LIF-LII image of a fiber-supported burning fuel droplet ( $n$-decanc) produced by 266 nim excitation and (b) LII image of a similar droplet using 1064-nm excitation light. Fach image was obtained $300 \mathrm{~ms}$ after ignition. The spatial scale is in millimeters. In each image the droplet is spatially located just below the ruler top exdge

precursor material and characterized the material transformation processes via laser-induced fluorescence (LIF) measurements of PAIIs (soot-inception species) and laser-induced incandescence (LII) measurements of soot (final product) within sootcontaining diffusion flames.

Thus, the purpose of this paper is to combine LIFI.II measurements to identify the spatial location of the chemical and physical transformation of material toward solid carbonaceous material. Then this transformation is optically characterized with these optical measurements. LIF has successfully monitored PAIs within both premixed $[11,13]$ and diffusion flames [1-3,16,19,20]. Similarly, III has revealed soot concentrations in both one- and two-dimensional imaging configurations [21-25]. Previous combined LIF-LII measurements did not examine the transition between the LIF and LII signals along a well-defined streamline such as exists along the axial centerline of a gas-jet diffusion flame [1,24]. In this paper, simultaneous two-dimensional LIF-LII images of both a normal and inverse diffusion flame (IDF) are presented and characterized by the excitation wavelength dependence and temporal decay characteristics of the signals. The spatial identification provided by the combined LIF-LII images allows precise thermophoretic sampling measurements to be made with detailed characterization of the sampled material via both bright-and dark-field TEM.

\section{Experimental}

Light at 1064 and $266 \mathrm{~nm}$ was used for LII and combined LIF-LII measurements, respectively. An $8 \times$ Galilean telescope of spherical UV fused silica lenses followed by a pair of cylindrical lenses formed the laser beam into a sheet of $20 \mathrm{~mm}$ height. The intensity for the $1064 \mathrm{~nm}$ light sheet was estimated to be $2.5 \times 10^{7} \mathrm{~W} / \mathrm{cm}^{2}$ based on a $10 \mathrm{~ns}$ laser pulse and sheet thickness of $750 \mu \mathrm{m}$. Using a $5 \mathrm{~ns}$ pulse width (FWHM) and 300- $\mu \mathrm{m}$ sheet thickness for the 266-nm light yielded an approximate intensity of 9 $\times 10^{6} \mathrm{~W} / \mathrm{cm}^{2}$. For two-dinensional images, a gated intensified camera fitted with an ultraviolet $f 4.5 / 105$ $\mathrm{mm}$ (adjustable) focal length camera lens and extension tube captured the LII and/or LIF images. A bandpass filter centered at $400 \mathrm{~nm}$ with $70 \mathrm{~nm}$ FWHM bandwidth preceded the gated intensified array camera for both the LII and simultaneous LIFLII measurements. The spatial resolution was approximately 27 pixels per millimeter. A frame grabber was used to digitize the images for transfer to the host computer.

The first flame system studied was a fiber-supported burning fuel droplet that presents a (normal) diffusion flame where the entire fuel source and pyrolysis region is enclosed within the flame front, preventing oxidative pyrolysis. The small spatial scale associated with such an envelope flame is well matched to the spatial dimensions of the TEM grid. Individual $5 \mu \mathrm{L}$ droplets of $n$-decane ignited by a spark served as the fuel for the droplet flame. A beam block shielded the droplet from the laser light to prevent potential laser-droplet interactions.

The second flame system chosen was an inverse diffusion flame. An oxidizer flow rate of $470 \mathrm{sccm}$ with an $\mathrm{O}_{2} / \mathrm{N}_{2}$ ratio of 22.5 issued from a $17-\mathrm{mm}$ (i.d.) tube while a fuel- $\mathrm{N}_{2}$ flow rate of $5.0 \mathrm{slpm}$ with a $\mathrm{C}_{2} \mathrm{H}_{4} / \mathrm{N}_{2}$ ratio of 0.4 flowed from a surrounding annulus of $47 \mathrm{~mm}$ (i.d.). Hastalloy honeycomb $(0.064$ cell size $\times 1.25 \mathrm{~cm}$ thick $)$ preceded by a layer of glass beads ( $3 \mathrm{~cm}$ thick) served as flow straighteners. An outer shroud ( $73 \mathrm{~mm}$ inner ring diameter) of $\mathrm{N}_{2}$ at roughly $25 \mathrm{slpm}$ stabilized the flame and also served to dilute unburned fuel gas before venting. To eliminate the effects of room drafts, a $70 \mathrm{~mm}$ O.D. quartz tube fitted with slots for sampling access sat atop the outer portion of the burner. With the fuel source surrounding the central oxidizer jet, thermophoretic sampling within the fuel-rich side of the diffusion flame is readily accomplished without penetrating the flame front, thereby minimizing probe-induced disturbance of the flame. Thermophoretic sampling was accomplished using an airactuated piston driving a rod holding the TEM grid holder and grid [26].

\section{Observations}

Figure la presents a simultaneous LIF-LII image of a fiber-supported burning fuel droplet using 266 


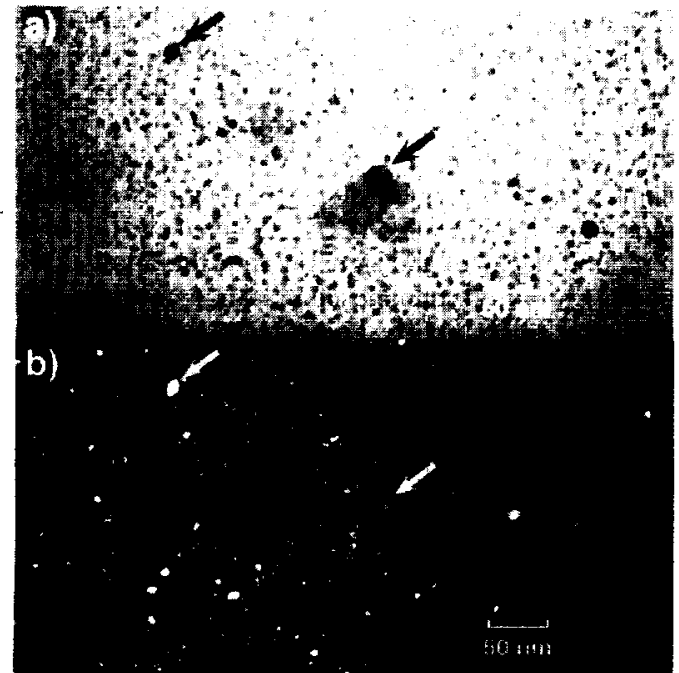

FIG. 2. (a) Bright-field TEM and (b) dark-field TEM of thermophoretically sampled material from within the dark region illustrated in Fig. la. The markers indicates common reference points in each pancl.

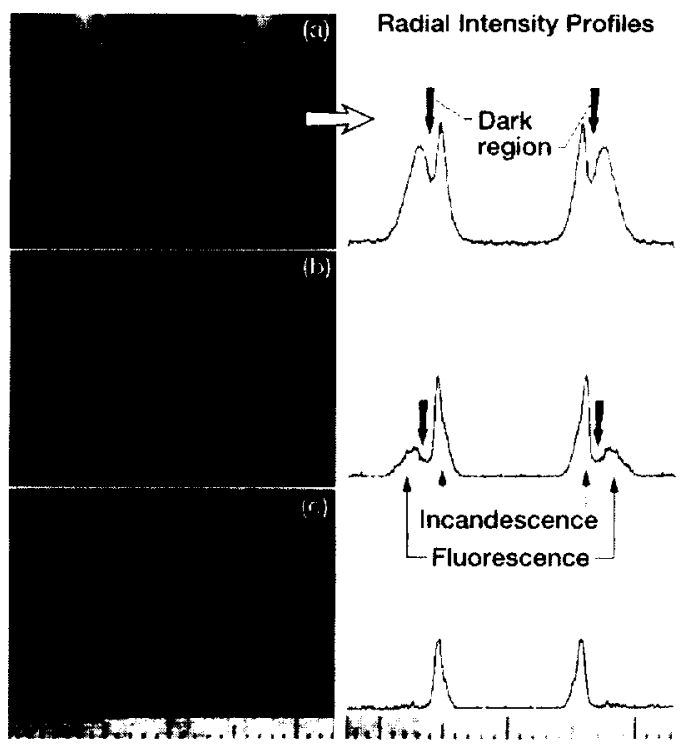

FIG. 3. Simultaneous LIF-LII inages of an inverse diffusion Hame of $\mathrm{C}_{2} \mathrm{H}_{4}$ with radial intensity profiles obtained at a height of $13.5 \mathrm{~mm}$ above the bumer. The spatial scale is in millimeters. Ten individual LIF-LII images were averaged together $t$ o obtain the panels shown in the figure. Each image was obtained using the same camera intensifier gain and gate duration. The different images correspond to different signal collection time delays after the excitation laser pulse and are (a) 40 ns, (b) $80 \mathrm{~ns}$, and (c) $160 \mathrm{~ns}$ nm excitation light, while Fig. Ib presents a LII image obtained using 1064-nm light. This excitation wavelength dependence can be used to distinguish molecular fluorescence and soot incandescence as discussed later. The laser-induced emission (LIE) intensity in Fig. 1a decreases with increasing distance (or equivalently residence time) above the droplet, passes through a minimum, hereafter referred to as a dark region, and then increases, whereas only LIE intensity in the far wake region is seen in Fig. 1 b.

Figure 2a shows a bright-field TEM image of the thermophoretically collected material from within the dark region illustrated in Fig. Ia. Numerous small, individual particles are observed. From the indicated magnification, the particle sizes range from $1-4 \mathrm{~nm}$ with an average size of $3 \mathrm{~nm}$. Figure $2 \mathrm{~b}$, shows the corresponding dark-field image of the same material shown in Fig. la. The dark-field TFM image shows that each individual particle consists of two to three bright points, hereafter referred to as crystallites.

Figure 3 shows a serpuence of LIF-LII images of the inverse diffusion fame along with radial intensity profiles where for each image, the burner surface lie's $1 \mathrm{~mm}$ below the lower edge of the image. As shown by both the images and the corresponding radial intensity profiles (corresponding to the arrow location in Fig. 3a): a minimum in the LIE internsit exists between the inner and outer ammular regions. Similar to the droplet flame, this minimum in the combined LIF-LII intensity is also hereafter referred to as the dark region.

Figure 4a shows a bright-field TEM image of thermophoretically sampled material from within the dark region of Fig. 3. The low magnification provides an overview of the material variation along the indicated radial direction within the flame. Figure 4 h shows a higher magnification of material seen in Fig. 4a. A distinct contrast in both the shape definition and opacity to the electron beam is observed between the two structures shown in Fig. 4b. Interestingly, while the less-opaque object seems to possess a larger diameter than the other structure, it appears more transparent to the electron beam despite presenting more material in the electron beam pith. Figure 4c shows the corresponding dark-field TEM inage of the structures seen in Fig. 4b. The more-opaque structure' in the bright-field image contains many more crystallites in the dark-field image compared to the other structure. The fuzziness surrounding the less-bright object is not due to focusing (both structures lie within $200 \mathrm{~mm}$ of each other) but represents less-dense or less-crystalline material.

\section{Discussion}

\section{LIF-LII Signals}

Both the excitation wavelength dependence and radiative lifetime distinguish the LIF signal from the 


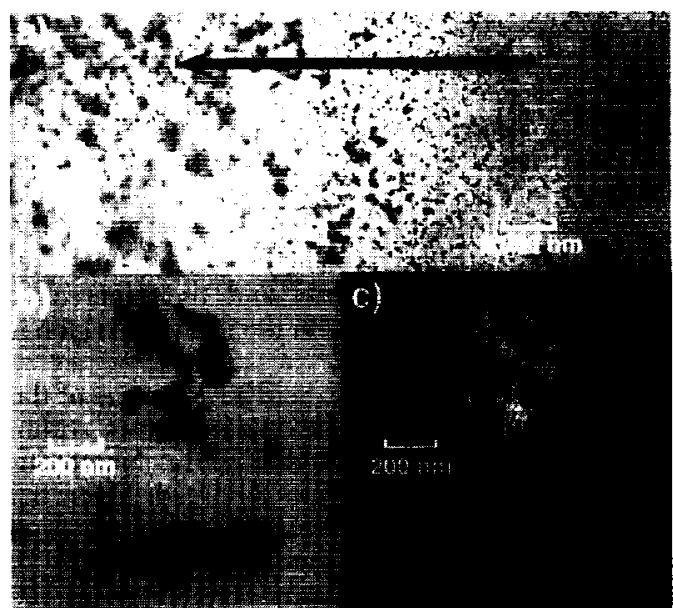

FIg. 4. (a) Bright-field TEM at low magnification illustrating the variation in soot morphology across the sootcontaining region. The arrow is directed radially outward The image is meant to convey the range of particle morphologies observed. (b) Bright-field TEM contrasting the soot morphologies observed in (a). (c) Dark-field TEM of the corresponding structures observed in (b). For ead image, the sampling height was $13.5 \mathrm{~mm}$ above the bumer.

LII signal in the images in Figs. 1 and 3, respectively. Light at $1064 \mathrm{~nm}$ will not produce molecular fluorescence in the visible, whereas $266 \mathrm{~nm}$ light is known to readily excite electronic transitions in a variety of combustion intermediates resulting in fluorescence $[27,28]$. To excite visible fluorescence, multiphoton absorption of $1064 \mathrm{~nm}$ light that could occur through a nonresonant multiphoton absorption process is necessary. Not only is infrared multiphoton absorption improbable given the laser intensities used, but even if it did occur, it would likely result in molecular dissociation from the ground electronic state, which generally does not lead to photof ragment emission [29]. Thus, the presence of signal in the near-wake region using $266 \mathrm{~nm}$ excitation and its absence when using 1064-nm light indicates that this signal is $L I F$, likely arising from $P A H$ fluorescence. Since both 1064 and $266 \mathrm{~nm}$ light is readily absorbed by soot, at sufficient intensities, each excitation wavelength is capable of producing LII [16]. Thus, the similar spatial extent of the laserinduced emission signal in the far-wake region of Figs. $1 \mathrm{a}$ and $1 \mathrm{~b}$ using either 266 or $1064 \mathrm{~nm}$ light indicates that this LIE signal is LII.

While fluorescence from PAIIs within diffusion flames is generally detectable only tens of nanoseconds after laser excitation $[3,16]$, LII is detectable hundreds of nanoseconds after the laser pulse at moderate laser intensities [16,2]-25]. The slower temporal decay of LII compared to fluorescence results from cooling processes, which determine the
LII signal decay, being slower than collisional quenching, which determines the fluorescence decay rate within atmospheric pressure flames [16]. Thus, the rapid temporal decay of the LIE signal in the outer annular region of the inverse diffusion Aame shown in Fig. 3 indicates that this signal is molecular fluorescence (LIF). Conversely, the long temporal decay of the signal within the annular extending hundreds of nanoseconds (in contrast to tens of nanoseconds for the fluorescence) confirms the identity of this signal as soot incandescence (LII).

\section{TEM Images}

\section{Droplet}

The small size $(1-4 \mathrm{~nm})$ of the particles seen in Fig. $2 \mathrm{a}$ is characteristic of those observed by other researchers as indicating the first incipient sont particles $[4,12,15,16]$. The internediate spatial location of these particles between the PAH-and soot-containing regions confirms the transitional role of sootprecursor particles in the soot-formation process. At slightly higher axial heights within the dark region shown in Fig. la, larger individual particles of greater than $5 \mathrm{~nm}$ diameter were found, indicating further mass growth.

Despite their small size and close temporal origin to molecular PAHs, the soot-precursor particles observed in Fig. 2 are crystallized. The bright points in the dark-field TEM image of Fig. $2 \mathrm{~b}$ are interpreted as crystallites appropriately oriented to diffract a portion of the electron beam into the viewing angle. In fully formed carbon black particles, X-ray diffraction has shown each particle to be made up of a large number of crystallites $\left(\sim 10^{+4}\right)$ [30]. Each crystallite consists of 5-10 sheets of carbon atoms with each she'et having a length or breadth of $20-30 \AA$. A random packing of such crystallites is commonly considered amorphous carbon [30]. Diffraction from ordered carbon layer planes indicates carbonization of these precursor particles has occurred, with the chemicall/physical structure no longer resembling a "clump" of condensed hydrocarbons but rather a disorganized solid. Such a rapid material transformation is feasible because LMMA analysis of soot precursor particles collected within an ethylene-air diffusion Hame indicates that graphitization of sootprecursor particles can occur rapidly, $(\sim 10 \mathrm{~ms})$, resulting in a particle hydrogen mole fraction, $X_{H}$, of 0.15 , typical of mature soot released from flames [12]. As the transparency of these structures increased in the bright field TEM images, the number of crystallites within these structures decreased, as observed in the dark-field TEM images. In summary, these results indicate that carbonization proceeds rapidly compared to mass growth for the sootprecursor particles in the droplet flame. 
Inverse Diffusion Flame

Numerous soot-formation/growth studies have used shock tubes $[9,31,32]$, flow reactors $[8,10]$, and in situ probe sampling within premixed $[4-7]$ and diffusion flames $[2,20,33]$. With the exception of the carbon black industry, few fuel pyrolysis studies have used TE.M for prodicet morphological analysis. One particularly revealing study, however, sampled the exhaust within a flow tube reactor of $2 \%$ benzene in $\mathrm{N}_{2}$ at $13833 \mathrm{~K}$ at different positions (residence times) [10]. With increasing residence time, the rapid decrease in the extractable tar content coincided with an equally rapid increase in the carbonaceous residue content of the sampled material. TEM micrographs of the sampled material at early residence times $(<50 \mathrm{~ms})$ revealed a condensed phase of semitransparent tarlike material existing in large "globs," far different than the usual chainlike structures normally associated with soot. Icreafter, the term tarlike is used to clenote a disorganized, unstructured solid material (potentially a highly viscous "liquid" at Hame temperatures) with both a lower degree of crystallinity and $\mathrm{C} / \mathrm{H}$ ratio compared to ordinary soot commonly observed.

The TE.M obsenvations in the inverse diffusion Hame shown in Fig. 4 are consistent with these results. As seen in the bright-fiehl TEM image of Figs 4b, the decreased opacity despite the larger size indicate's that the tar-like inaterial appears less clense to the electron beam. The relatively miforn opacity of the tarlike material suggests a rather miform composition. Far less crystallinity of the tarlike substance is revealed by the markedly lower intensity in the dark-field TEM image of Fig. $4 \mathrm{c}$ compared to the normal-appearing soot aggregate. The chainlike resemblance of the tar-like substance indicates that agglomeration of the pyrolytic material has occurred before carbonization $[\$, 10]$. The poorer geometrical outline is comsistent with the formation of the tarlike aggregate via pyrolytic cleposition.

Just as for normal diffusion flames, the fuel-rich side of the inverse diffusion flame closely resembles a pyrolytic system with the flame front presenting an oxygen harrier. In this context, the present results indicate that rapid deposition of prolytic material (nlass growth) occurs before significant carbonization $[8,10]$. This accounts for the rather uniform tarlike appearance of the structures shown in Fig. 4, the lack of opacity in the briglot-fickld TEM images (Figs. 4 a and $4 b$ ), and the lack of crystallinity in the dark-field TEM inage (Fig. 4c). While the images in Fig. 4 do not prove soot formation ocenrring via carbonization of larese tar-like structures, they do indicate that significantly different relative rates of soot-precoursor material nucleation, conalescence, and growth occur relative to carbonization in this flame system compared to the droplet flame (normal diffusion flame), resulting in verv different material properties compared to normal earbonaceous soot ats discrussed next.

\section{The Dark Region}

As seen in Figs. 1a and 3 , a minimum occurs in the combined LIF and L.II intensity spatially located between the $\mathrm{PAH}-$ and soot-containing regions. The fluorescence intensity decrease is likely due to three factors: (a) an increase in the size of PAHs through molecular growth, (b) a decrease in the gas-phase PAH concentration, and (c) PAII coalescence into soot-precursor particles. As PAIIs grow in size, the number of rovibrational and electronic quantum states increases dramatically [34]. With an increased guantum state density, nonradiative transitions between electronic states increases because of increased coupling between these states [34]. Thus, the fluorescence quintum vie ld decreases. Secondly, as the PAHs coalesce into particles, the gas-phase number concentration of PAH decreases since large PAIS presumably serve as building blocks for sootprecursor particles, while small PAHs serve as initial mass growth material for the precursor particles [35.36]. Thirdly, as carbonization continues, the PAI1 "molecules" lose their individual identity and become assimilated into an object that is becoming more solid in form. With increasing solid structure, the probability for nomradiative decay increases dramatically because of the far higher quantum state density [37]. Thus, while the particle readily absorbs light and may still fluoresce because the constituent "molecules" possess highly ahsorbing chromophoric groups, with increasing carbonization, the fluoresconce quantum vield decreases relative to isolated gats-phase molecules, eventually becoming negligible. These three factors accomnt for the decrease in Huorescence intensity with increasing axial height seen in Fig. la. Similarly, the probability for nomradiative decay is greatly increased in condensed and/ or partially carbonized tar-like material relative to gaseous species, thus accounting for the fluores'ence intensity decrease with decreasing radial distances seesl in Fig. 3.

With increasing solid character of the particle rapid intenal dissipation of energy deposited through multiphotom absorption occurs [38]. If a sufficient mumber of photons is absorbed, the particle will be heated to incandescence temperatures. The detaiked chemical and physical structure of the particle will determine the fate of the particle upon rapid, high-energy deposition. Very small soot-precursor particles are thought to possess a high numher of reactive radical sites accomting for the rapid mass growth [35]. This large mumber of reactive sites indicates that the extent of bonding of the aromatic structures within the compound is very incomplete. Upon rapid energy deposition, bonds linking aromatic units to the solid structure may sever, leading 
to fragmentation. Until bonding of adjoining molecular units is substantially complete, fragmentation of the particle will likely occur during the energy deposition process, resulting in minimal or no incandescence. Similarly, the tar-like objects that are only partially carbonized may be intermediate between molecular and solid structures [9-11,32]. If enough energy accumulates within the particle through absorption of multiple photons (not necessarily simultaneously), molecular fragmentation rather than incandescence would more likely occur given the largely molecular structure. Thus, during this transitional period in which significant chemical and physical material transformation processes are $o c-$ curring, both nonradiative transitions and/or fragmentation are likely to result from laser excitation. Conseruently, minimal intensity is observed in either the LIF or LII signals, thereby accounting for the dark region observed in the simultaneous LIFLII images.

These changes in the photophysical properties reHect the chemical and physical transformation in material properties occurring between molecular material (condensed or gaseous) and solid carbonaceous soot. This transformation appears general despite the very different apparent relative rates of soot-precursor material growth and coalescence versus carbonization within the normal and inverse diffusion flames. Both the decreasing opacity with increasing radial distance (or increasing tar-like appearance) of the soot structures seen in the briglitfield TEM images of Figs. $4 \mathrm{a}$ and $4 \mathrm{~b}$ and decreasing crystallinity seen in the dark-field TEM image of Fig. $4 c$ reveal a consistent physical/chemical change in the material composition. With increasing radial distance from the centerline in the inverse diffusiom Hame, the material changes from a disorganized yet highly crystalline solid to barely visible condensed molecular matter. A similar material transformation is suggested by the soot-precursor particles observed in Fig. 2. In contrast to the large structures observed in Fig. 4, the initial small structures and subsequent growth suggest a soot-formation process proceeding through chemical and physical condensation of large molecules (PAHS) followed by mass addition concurrent with carbonization. Irrespective of the relative rates, surface mass growth, coalescence, and carbonization are all critical processes leading to solid carbonaceous soot

The observed optical properties of the soot structures also vary in a spatially similar manner. With decreasing radial distance, the LIF intensity (with no apparent contributing LII signal) decreases from a maximum reaching a minimum spatially overlapped with an intensity minimum in the LII signal as seen in Fig. 3. At smaller radial distances, the LII intensity increases, reaching a maximum still on the fuel-rich side of the diffusion flame. Analogous behavior is observed in the normal diffusion flame with increasing axial distance above the burning droplet. At small axial heights within the normal diffusion flame and large radial distances within the IDF, no material was collected via thermophoretic sampling as would be expected if only gaseous species were present. In these regions, only fluorescence is observed. At high axial heights in the normal diffusion flame or small radial distances in the IDF flame, only solid carbonaceous soot was found through TEM analysis of thermophoretically sampled material. In these regions, only incandescence is observed.

Thus, the postulated variation in material photophysical properties suggested by the spatial variation in the LIF and LII intensities is supported by the spatial variation in the material composition as revealed by both the bright- and dark-field TEM images. Most significantly, the minimum in the combined LIF-LII intensities is indicative of the chemical and physical changes accompanying the transformation of molecular matter into solid carbonaceous soot regardless of the specific soot formation route. On this basis, the dark region illustrated in the simultaneous LIF-LII images spatially locates the region containing soot-precursor material.

\section{Conclusions}

Simultaneous LIF-LII images are valuable for visualizing both PAH and soot-containing regions within both transitory (droplet) flame and steadystate IDF flames. The LIF and LII signals may be distinguished either by the excitation wavelength dependence or the temporal decay following the laser pulse. As revealed in the LIF-LII images, a dark region appears juxtaposed between the PAI and soot-containing regions. TEM measurements of thermophoretically sampled material from within this dark region suggest very different rates of sootprecursor material growth and coalescence versus carbonization within the normal and inverse diffusion flame. Postulated photophysical properties accounting for the minimal LIF and LII intensity (the "dark" region) observed in the LIF-LII images are supported by both bright- and dark-field TEM measurements of the sampled material. Both the spatial position of the dark region and TEM measurements indicate that the dark region represents a transformation region. In this region, the chemical and physical material conversion between gaseous or condensed molecular species (soot-precursor material) and solid carbonaceous soot particles occurs.

Acknowledgments

Support under NASA contract NAS3-27186 with Nyma Inc, for this work is acknowledged. The author extends special thanks to Mr. David Hull of NASA-Le RC for perform- 
ing the TEM measurements and for helpfiul discoussion regarding TEM

\section{REFLRENGES}

1. Ni. T. Guptat, S. B., and Santoro, R. J., Ternty-Fifth Sympesium (International) on Combustion, The combustion Institute. Pittsburgh, 1994. pp. 5855-592

2. Prado, G., Garo, A, Ko, A., and Sarofion, A., Thernizth Symposium International) on (ombustion. The Combustion Institute, Pittshurgh, 1984, pp. 989-996.

3. Gome\%, A. Littman, M. G., and Gilssmant. I., Combust. Flame $702225-241$ (1985)

4. Wersborg. B. [.. Fox. L. K., and Howard, J. B.. Comlnest. Flame 24:1-10(19)75).

5. (Biajolo, A., D) Anna, A., Barletlla. R. and Tregrossi, A.

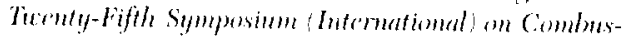
tiom. The Combustion Institute. Pittshurgh, 1994. pp. $679-685$.

6. Bittuer, J. D. and I Ioward, J. B., Eighternth Sympesium (Intermational) on (Combustion. The Combustion Institute, Pittshurgh, 1981. pp. 1105-1116.

7. MeKimon, J. T. and Howard, J. B.. Ternty-Fonth Sizmposinm ! International on Combinstiom. Tlec Combustion lnstitute, Pittshurgh. 1994, pp. 965-972.

8. Lahlave, J and Prado, (c., Cartom 12:24-31 (1974).

9. Craham, S. C., Homer, J. B., and Rosenfeld, J I. J., Prox. R. Sox Lomelen, Ser A 344259 -255 (1955)

10. Iallaye, J. in Paticulate ('arton Formation doring (ombustion. (Sieglia, D). C. and Smith, (;. W. Eds) Plemum Press New York, 1981, p. 14:3

11. DAlessio, A., Cambi. (;., Minutolo, P.. Russo, S., aund DAma, A. Thenty-Fifh Symposinm International ! on Combustion. The Combustion Institute, P'ittshurgl, 1994, pp. 64.5-6.51.

12. Dobbius, R. A., Fletcher. R. A., and I, W. Combust Hom, 100:301-300) (1995)

13. Haymes, B.S., fander, II., and Wagner. II. (;., Ber

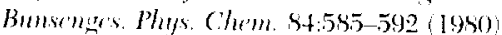

1.t. Sintero, R. J and Semerijian, II. G., Texentieth Sympesinm intermational! on Combustion, The Combustion Institute. Pittshurgl, 1994, pp. 997-1006\%.

15. Dobins, R. A. and Sulramamiasivan, H., in Sont For mation in Combnstion, (Borkhorn. H.. Fd.). Springer Verlag. Heidelloerg. 1994, p. 290.

16. Vunder Wall, R. I... Jensem, K. A, and Choi, M. Y. Comblust Flamer, 19966, accerpted

17. Megaridis, C. M. and Dobblins. R. A. Thentu-Soromd
Symposimm intervational on Combustion, The Comhustion Institute, Pittshurgh. 1998. pp. 353-3632.

15. Megaridis, C: M. and Dobbins, R. A., Combust Sci Trethol. 71:95-109 (1990).

19. Petarcat. I. and Marconi, F. Combust. Fane is:30s $325(1959)$

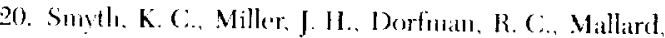
W. G. and Satutoro, R. J. Combust. Flame 62:15i-1s1 $(195.5)$.

21. Vander Wal, R. I. and Wroland, K. J., J Appl. Phys. B $59)+45-454(1994)$

22. Vander Wal, R. L. and Deetricl, D. L., Appl Opt. $34: 1101-1107(199,5)$.

23. Sharddix, C. F., Harrington, J. E., and simeth. K. C... Comblust. Flan 99:72:3-732 (1995)

24. Cignoli. F. Beneechi. S., and Zizalk, (s.. Appl opt. $33.5775 .5752(1994)$

25. $\mathrm{Ni}, \mathrm{T}$, Pinson, J, A. Couptia, S. and Santoro, R. J. Appl. Opt. 34:705:3-7091 (1995)

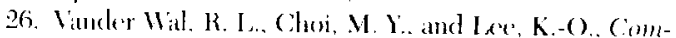
bust. Flame 102:200-204 (1995).

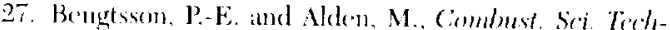
nol. $76: 307-318(199)]$

28. Beretta, F. D. Alessio, A., DOOrsi, A. and Minutolo. P., Combust. Sci. Terhol 85:455-470 (1992).

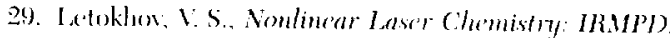
Bristol, Ning York. 1985.

30. Palmer, H. B. and Cullis, C. F. in Chemistry and Physirs of Carlom, Vol. 1 (Walker. P. L. Ed Marcel Dekker. New York, 1965.5, p. 26.5 (and references tlecreine

31. Frenklacl, M., Taki. S., and Matula. R. A. Combust Flame 45):275-282 (1985)

32. Crabatm, S.C., Sixternth Symposium dnternationat an Combustion, The Combustion Institute. Pittshurgh. $19-56$. pp. $663-669$

33. Hepp. H. Siegmam, k, and Sattler, K. (Chem. Phy. Letl. 23:3:16-22(1995)

34. Strinfeld, J. I. Molecules and Radiation: An Butrodusfion to Modern Molecelar Spectrosecopy. Tla MIT Press, Cimbridge, 1981, pl). 169-225.

3.5. Howard. J. B. Theenty-Third Sympasium (Intemational) on combustion. The Combustion Institute. Pittshurgl, 1990, pp. 1107-1127

36. Marr. J. A. Cionane, L. M. lomgell, J. P.. Heward


$101: 301-309)(1994)$

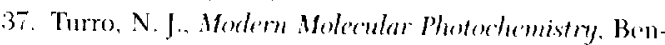
jamin/Cummings Meolo Park, (A. 19is, pP. 153-195.

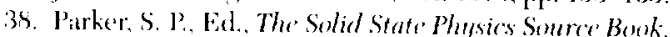
Mccraw Ilill, New York, lass pp. 95-19s. 
